\title{
Research on Development Strategy of Agricultural Products E-commerce Logistics in Weihai Area
}

\author{
Mengting Jiang*, Hanping Hou \\ School of economics and management \\ Beijing Jiaotong University \\ Beijing, China \\ 1103040511@qq.com
}

\author{
Shaoqing Geng, Xuehui Wang \\ School of economics and management \\ Beijing Jiaotong University \\ Beijing, China
}

\begin{abstract}
In 2017, the scale of e-commerce for fresh agricultural products in China reached 139.13 billion yuan, an average annual increase of $50 \%$, and it is expected to exceed 150 billion yuan in 2018. Presently, the poorly developed situation of agricultural products in Weihai leads to a large room for improvement. To increase the added value of agricultural products, save circulation costs and increase the gross national product, This paper takes agricultural products e-commerce logistics as the research object. Using interview and organizing the relevant literatures, I summarize the status and problems of agricultural e-commerce logistics in Weihai, and draw appropriate solutions. Especially, in terms of logistics speed and logis tics quality, it is difficult to meet customer requirements. Weihai has abundant agricultural resources and develops ecommerce logistics of agricultural products, which is conducive to the establishment of a modern agricultural product circulation system and the realization of the circulation value of agricultural products. It plays an important role in improving the comprehensive competitiveness of agricultural products and promoting the rapid development of the economy.
\end{abstract}

Keywords-Agricultural products; E-commerce logistics; Brand; Standard system

\section{INTRODUCTION}

According to statistics in 2017, fresh consumption is mainly in first- and second-tier cities. Younger users with the highest education level become the main group. Middle-class families are the main force of online fresh consumption. Individuals with monthly income of over 8,000 yuan account for $43.6 \%[6]$.

With the development of the Internet, e-commerce has gradually entered the lives of consumers. There are more than 4,000 e-commerce companies operating agricultural products nationwide, but only $1 \%$ of the profits, $7 \%$ of the huge losses, the main reason is related to logistics. It can be seen that there are many problems in the current agricultural product ecommerce logistics .It needs to be improved.

\author{
Jianliang Yang \\ School of economics and management \\ Beijing University of Chemical Technology \\ Beijing, China \\ yangjianliang6265@126.com
}

\author{
Yue Wang \\ Assistant Engineer \\ Space star technology co., LTD \\ Beijing, China \\ Lixueb2141@163.com
}

\section{CONCEPTION}

\section{A. Agricultural products}

Farm produce is an item produced in agriculture, such as sorghum, rice, peanuts, corn, wheat, and souvenirs in various regions[5].

\section{B. Agricultural products e-commerce platform}

The agricultural product e-commerce platform refers to a website platform that uses modern information technology to provide business operations in the field of agricultural products with business transactions such as sales, purchase and electronic payment of products or services online. Agricultural product e-commerce is a brand-new business activity model, which makes full use of the Internet's ease of use, wide-area and interoperability to achieve fast and reliable networked business information exchange and business transactions.

The characteristics of the agricultural product e-commerce platform:

Breaking the traditional time and space, geographical restrictions, and expanding agricultural product circulation.

Make market information more transparent, reduce the problem of slow sales caused by lack of sales channels.

Promote agricultural products, achieve resource integration and make the industry develop more smoothly.

\section{Agricultural Products E-commerce Logistics}

Maybe, agricultural products e-commerce logistics = agricultural products e-commerce platform + logistics. On the surface, it involves two major entities, the actual operators of agricultural products e-commerce platform and related logistics personnel. Logistics is the physical flow of goods from the place of supply to the receiving place. According to actual needs, the basic functions of transportation, storage, 
loading and unloading, handling, packaging, distribution processing, distribution, recycling, and information processing are organically combined. The agricultural product ecommerce logistics has the characteristics of high cost and large loss.

\section{STATUS AND PROBLEMS OF AGRICULTURAL PRODUCT E- COMMERCE LOGISTICS IN WEIHAI AREA}

\section{A. Status of agricultural products e-commerce logistics in Weihai area}

Consumers are not satisfied with the current performance of agricultural products e-commerce logistics in Weihai. It may be because of the special attributes of agricultural products. Many agricultural products are not convenient for online purchase. For example, fig skin is soft and fig can't be easily stored.

Current consumers are more inclined to buy offline. The first reason is the geographical location. The supermarket and the farmer's market are close to the consumer's residential area, and the purchase is convenient. Secondly, the cost is cheap. After the order is placed, the courier company needs to be transported, which costs time and costs.

There are more problems in the transportation process of the products. The speed of logistics and the quality of logistics all affect the quality of the products. The logistics speed is too slow, the agricultural products are perishable, and the frozen aquatic products are easy to be frozen. The quality problems in the transportation process are mainly due to the deterioration of the products. Among them, the first two account for a larger proportion. Rotting deterioration is generally caused by the transportation process. There are many reasons, including transportation speed is too slow, transportation packaging is unreasonable, the requirements for special products in transportation are not met, and the courier personnel are not operating properly.

For agricultural products e-commerce companies, their ecommerce platform has no visibility, and has no ability to establish their own logistics department, and can't effectively reduce logistics costs. Consumers pay too little attention, so sales are not much. Taobao shop owners will choose a courier company, generally default to a certain express. Because the price of the main products of Taobao shop is low, there is no financial strength.

\section{B. Problems in the e-commerce logistics of agricultural products in Weihai}

- The demand is large, in Weihai e-commerce platform has a small popularity. On January 18, 2018, the data released by the National Bureau of Statistics showed that in 2017, the national online retail sales amounted to RMB 7.1751 billion, a year-on-year increase of $32.2 \%$. On a large scale, the increase in the number of Internet users and the successful transformation of the e-commerce market have increased the determination of consumers to "catch their hands". However, as far as the Weihai area is concerned, whether it is an agricultural product e-commerce enterprise or a Taobao shop owner, the local e-commerce platform is too small in popularity, there is no market, the e-commerce output range is small, and the output is small.

- Insufficient brand development and insufficient competitiveness. The agricultural products in Weihai are not as good as the Yantai apples and the pears in Laiyang. The first reason is that planting is scattered, the planting area is small, it is not enough to form a scale, and it is difficult to form a brand. Second, the awareness of brand building for agricultural products is weak, and there is a lack of relevant knowledge-based talents to carry out brand building for Weihai regional agricultural products.

- There are many logistics links and the cost is too high.

In recent years, vegetables and fruits in Weihai have been sold more expensive than meat. One of the reasons is that the logistics cost of agricultural products transportation is too high. Among the total cost of production and sales of agricultural products, the proportion of production costs is low, and the postproduction links such as acquisition, transportation, processing, and sales account for a large proportion. Therefore, the agricultural e-commerce logistics in Weihai has not really developed. At the same time, the information on supply and demand is asymmetrical, farmers are not familiar with the price of the ecommerce market, and there is a phenomenon of low acquisition and high shots. For example, in recent years, "Brutal Garlic ", "Mad Corn", "Play with beans" ..... The network language makes people laugh and laugh is the best embodiment of the status quo.

- The quality of agricultural products is difficult to guarantee. At present, there are different levels of safety hazards in all aspects of agricultural products ecommerce logistics in Weihai. At present, the real-time monitoring system for agricultural products in Weihai has yet been built, and the monitoring efforts need to be strengthened. These prevention systems strictly control the quality of agricultural products. And the problems in the e-commerce logistics environment are more serious.

- Agricultural products e-commerce logistics information is low. The agricultural e-commerce logistics in Weihai is still in its infancy. Young people are the main customers. The market size is limited to Weihai. The logistics informatization level and information interaction of agricultural products operators in Weihai area are insufficient. Not timely, unresponsive, and insufficient customer satisfaction[3].

\section{THE SOLUTION TO THE PROBLEM OF AGRICULTURAL PRODUCTS E-COMMERCE LOGISTICS}

\section{A. Increase the visibility of e-commerce platforms}

In order to increase the popularity of the platform, firstly, we must have our own APP, and then increase the propaganda, first pilot operation in key areas of Weihai; secondly, increase 
the incentives on the APP to increase the consumer's goodwill; finally, increase the exposure rate .

\section{B. Mobilize resources of all parties and implement "brand" cultivation actions}

First, Weihai should clarify which agricultural products we can build brand advantage. Then, to advantage agricultural products, increase the construction of agricultural product brands. We should implement "media + e-commerce platform". We need to tell others the story of the brand and tell the story of Weihai.

\section{Improve the cold chain logistics standard system}

Improve the cold chain logistics standard system, formulate and promote a series of cold chain logistics operation specifications and technical standards covering the entire chain, and create a standard for cold chain logistics [1]. Vigorously develop the retail mode of agricultural products such as "agricultural enterprise docking" and "e-commerce + cold chain logistics + smart kitchen cabinet" to promote the construction of a cold chain information platform.

\section{Improve the industrial chain}

To strengthen the post-production "packaging, marketing and transportation" activities of agricultural products, it is necessary to realize that the main short-term development of agricultural products is that the basic industrial chain of agricultural products is still not perfect and needs to be strengthened. The development of agricultural products ecommerce is backward, and the circulation of agricultural products e-commerce is lack of standardization. The development of agricultural products e-commerce can create a new industrial chain, including agricultural production, acquisition, processing, warehousing, inspection, packaging, distribution, transportation, etc[4]. The construction of a complete industrial chain plays an important role in driving the economic development of Weihai .

\section{E. Make full use of e-commerce big data}

The company will seamlessly track the entire process of production, acquisition, processing, warehousing, inspection, packaging, distribution, transportation, etc., improve the supply standards of agricultural products, and improve the competitiveness of agricultural products in the e-commerce market. With the big data of agricultural products and ecommerce, according to the requirements of customers, we can also carry out personalized customization and scientifically arrange production[2].

\section{F. Other suggestions}

- Suggestions for fresh farmer's enterprises. For some small fresh farmer's enterprises, due to lack of management experience, professional talent resources, and abundant funds, in order to achieve cross-regional trade, some professional fresh-order enterprises can provide integrated solutions for them.
1) The customer does not place an order at the same time period. Flexible setting of the time of receipt. It can be set to prohibit the customer's ordering time, the downstream customer enters the system, the friendly reminder should pay attention to the deadline for submitting the order, standardize the order processing flow, avoid the cost increase caused by the scattered order after the order is completed or the customer dissatisfaction caused by not processing in time.

2) The fresh industry often changes its price. Change the price in batches. The system automatically calculates the average purchase price, supports the batch adjustment of the settlement price, and can simultaneously update the order price of the goods, effectively improving the work efficiency.

3) Ordering goods summary is easy to make mistakes. Fresh farmer's enterprises, in addition to online orders, generally have other forms of orders. Orders are received in various ways, and it is easy to make a single slip. Customers self-order, the system automatically aggregates orders, saving time and efficiency.

- Agricultural products often encounter high claims and provide fresh insurance for the express delivery industry. Based on the unique nature of agricultural products, the requirements for the speed and quality of agricultural products are relatively strict, which leads to the high cost of express delivery of agricultural products, and strict requirements for transportation timeliness of express delivery companies. Therefore, agricultural products are often rotted and degraded, and the courier company has no choice but to pay. The state should encourage Insurance company development of compensation for agricultural products.

- There are many logistics links and the cost is too high.

In recent years, vegetables and fruits in Weihai have been sold more expensive than meat. One of the reasons is that the logistics cost of agricultural products transportation is too high. Among the total cost of production and sales of agricultural products, the proportion of production costs is low, and the postproduction links such as acquisition, transportation, processing, and sales account for a large proportion. Therefore, the agricultural e-commerce logistics in Weihai has not really developed. At the same time, the information on supply and demand is asymmetrical, farmers are not familiar with the price of the ecommerce market, and there is a phenomenon of low acquisition and high shots. For example, in recent years, "Brutal Garlic ", "Mad Corn", 'Play with beans" ...The network language makes people laugh and laugh is the best embodiment of the status quo.

- The government adopts the pilot first, and "first rich" drives "post-rich". The Weihai government should first reform a number of vegetable bases, establish relevant green fruit and vegetable websites, and establish their own brands. Then they establish different product distribution cards in different communities, find out the key communities, first engage in free trials, increase the customer's goodwill, 
and promote the website to reassure customers; like roadside billboards, we must accurately locate people. In terms of express delivery, for the Weihai area, you can use your own transportation vehicles.

\section{CONCLUSION}

In this paper, according to the status quo, summarize the problems of the development of agricultural products ecommerce logistics, and finally the optimization measures are given.

At present, the agricultural product e-commerce logistics in Weihai is still in the initial stage, especially in terms of logistics speed and logistics quality, it is difficult to meet customer requirements. The competitiveness of agricultural products e-commerce logistics in Weihai is low and the market is small. Many consumers are not inclined to purchase agricultural products on the e-commerce platform. The series of problems also affect the consumer experience of purchasing agricultural products on the e-commerce platform. We need drastic changes to promote the development of agricultural ecommerce logistics in Weihai.

\section{REFERENCES}

[1] Qinggang $\mathrm{Wu}$, The Current Situation and the Countermeasures of China's Cold Chain Logistics Development, 2011.

[2] Y Mei, E-commerce Applications of Yiwu Market in the Age of the Internet , 2014.

[3] Yi Chen, Empirical study on the influencing factors of agricultural product supply chain management technology innovation in fujian and Taiwan, Fujian agriculture and forestry university, 2015. (In Chinese)

[4] Bin Song, Design and implementation of business processing and logistics distribution system for food enterprise, Hunan university, 2014. (In Chinese)

[5] Ran ZHANG, Sheng-wan FAN, Qiu WANG, "Journal of anhui agricultural university (social science edition)”, 2012,pp. 51-55.

[6] Jin-yan WANG, “Economic research guide”, 2016,pp. 21-22. 